\title{
Uebersicht der Arten der Gattung Dryops Oliv.
}

Gegeben von Edm. Reitter in Paskau (Mähren).

1" Glied 1 und 2 der gelben Fühler von Farbe des Körpers und in gleicher Weise sculptirt, das 2. blattförmig erweitert. Seitenrand des Halsschildes weder länger noch dichter behaart.

2" Halsschild quer, gewölbt, mit stark niedergebogenen Vorderwinkeln; die Zwischenräume der feinen Punktstreifen auf den Flügeldecken, namentlich die abwechselnden, leicht gewölbt. Tarsen von normaler Länge, das Klauenglied nicht deutlich länger als die übrigen Glieder. Long. $5-5.5 \mathrm{~mm}$. Europa. Illig. Mag. V. 219.

substriatus Müllr.

2' Halsschild quadratisch, oben schwach gewölbt, Punktreihen der Decken sehr fein, Zwischenräume gleich und eben; Tarsen sehr lang, das Klauenglied länger als die übrigen Glieder.

3" Halsschild hinten einfach, vor der Mitte ohne Ecke, Oberseite ausserordentlich gedrängt punktulirt, Flïgeldecken hinter der Basis nicht quer eingedrückt. Long. $7-9 \mathrm{~mm}$. Kankasus, Transkaspien, Turkestan. - Fedtsch. Reise in Turkest. II. 282. D. asiaticus Motsch. Kiesw.

longus Solsky.

3 ' Seiten des Halsschildes vor der Mitte zu einem lappigen, aufgebogenen Zahn erweitert, Oberseite fein aber äusserst gedrängt punktulirt; Decken hinter der Basis schräg niedergedrückt. L. 6-9 mm. Kaukasus. D. 1887. 257. angulicollis Reitt.

1' Glied 1 und 2 der Fühler schwach knotig verdickt, das 2. etwas stärker, aber nicht blattförmig erweitert und wie die übrigen Glieder gelb. Die Seiten des Halsschildes vorn, die Schulterbeule beim ơ länger und dichter, tomentartig braungelb befllzt. Von der Färbung der vorigen, Beine rostbraun, von normaler Länge (wie bei substriatus), die Hinterschienen am äusseren Spitzenwinkel dornförmig verlängert, Halsschild quer, wenig schmäler als die Decken, die Seiten vor der Mitte gerundet erweitert, die Vorderwinkel sammt dem vorderen Theile der seitlichen Halsschildwölbung niedergedrückt. Flügeldecken mit undeutlichen Streifen, dicht erloschen punktulirt, oben mit kurzen goldgelben Härchen besetzt; die Beine beim or mässig verdickt. Long. 5-6 $\mathrm{mm}$. Aegypten: Bad Helouan. Von Herrn Dr. Adalb. Fenyes gesammelt und demselben gewidmet.

Fenyesi n. sp. 


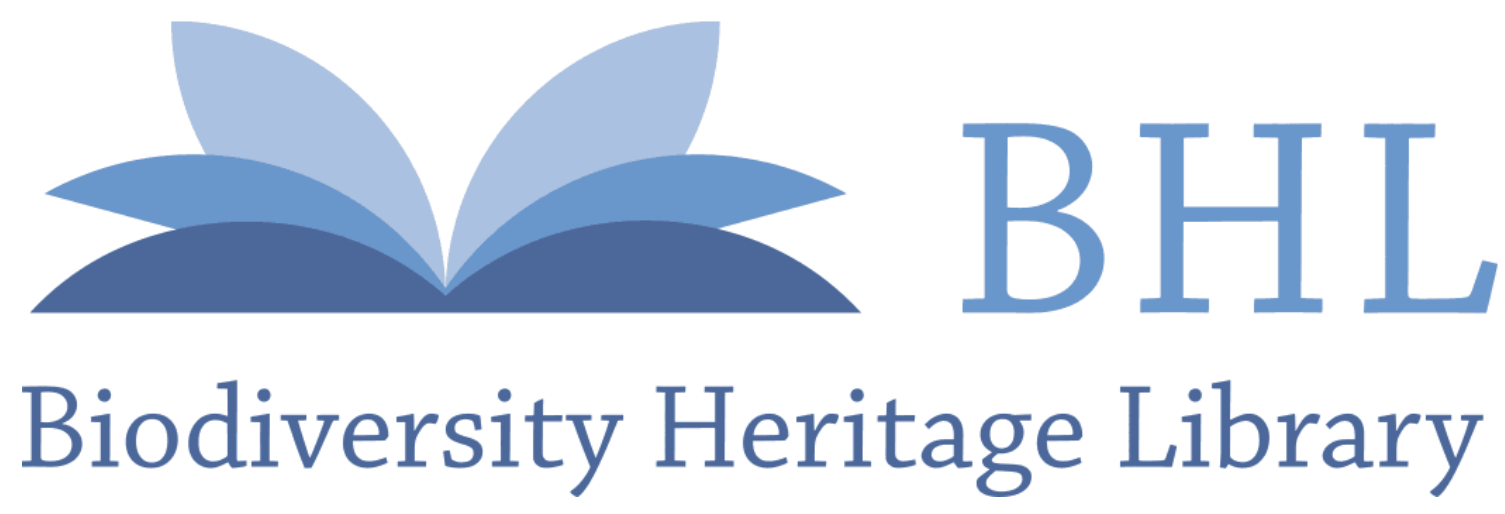

Reitter, Edmund. 1894. "Uebersicht der Arten der Gattung Dryops OLIV."

Wiener entomologische Zeitung 13, 313. https://doi.org/10.5962/bhl.part.13244.

View This Item Online: $\underline{\text { https://www.biodiversitylibrary.org/item/44103 }}$

DOI: https://doi.org/10.5962/bhl.part.13244

Permalink: https://www.biodiversitylibrary.org/partpdf/13244

\section{Holding Institution}

Smithsonian Libraries

\section{Sponsored by}

Smithsonian

\section{Copyright \& Reuse}

Copyright Status: NOT_IN_COPYRIGHT

This document was created from content at the Biodiversity Heritage Library, the world's largest open access digital library for biodiversity literature and archives. Visit BHL at https://www.biodiversitylibrary.org. 